\title{
Ego strength and methods of learning associations
}

\author{
SARA J. NIXON and N. JACK KANAK \\ University of Oklahoma, Norman, Oklahoma 73019
}

\begin{abstract}
High ego-strength subjects, determined by the Cattell $16 \mathrm{PF}$, were shown to be inferior to low ego-strength subjects in learning paired associations by the anticipation method, whereas the reverse was true when learning by the study/test method, when the list involved noncompeting materials. High ego strength is assumed to correlate with a high degree of control of responding tendencies and, hence, with a high response-confidence threshold. Learning is assumed to be retarded under the anticipation method due to competition within the method in the rapid alternation in retrieval and storage processes, which further heightens the confidence threshold, that of the high ego-strength subjects being above that of the low ego-strength subjects. On a competing task, the interaction did not occur, but significant effects were obtained for both ego strength (low inferior) and method such that the overall pattern of results suggested further insight into the processes affected by both ego strength and the two methods.
\end{abstract}

A number of studies (cf. Kanak \& Neuner, 1970) have found that the anticipation method of learning associations is inferior to the study/test procedure. Kanak and Neuner hypothesized that this inferiority results from an intrinsic source of competition in the anticipation method, deriving from the rapid alternation between test and study processes or retrieval and storage processes. This competition, in turn, was hypothesized to cause a general elevation of a subject's confidence threshold for responding, which should be reflected in a higher rate of omission errors as well as more trials to complete the response learning stage (Underwood \& Schulz, 1960), defined as the trial on which a given response is first given, whether correct or not. Ekstrand (1966) suggested that first-given response scores should be viewed as a measure of confidence threshold.

The present studies compare the anticipation and study/test methods in relation to the individual difference variable of ego strength (Cattell, 1957), extending earlier work by Duffy and Kanak (1975) with this variable. The individual variability in willingness to respond, or the setting of response-confidence thresholds, is a factor of considerable theoretical and practical interest in learning and memory, as well as in human performance tasks. Cattell proposed that ego strength accounts for an individual's "capacity for immediate integration and control of emotional reactions and bodily reactions" (1957, p. 103). Cognitive control of responding tendencies, regarded here as "bodily reactions" within the verbal or written realm, is implicated by this statement, and hence individuals of low ego strength are assumed to be less able to inhibit responses, in general, than are individuals of high ego strength.

Duffy and Kanak (1975) compared the anticipation and study/test methods as a function of high vs. low ego-strength subjects, predicting that high ego-strength subjects would produce higher first-given scores (i.e., inferior learning) under the anticipation method than would low ego-strength subjects, since a high level of control of responding would summate with a heightened confidence threshold induced by the anticipation method, relative to the study/test method, due to the intrinsic source of competition in cognitive processes within the method. Although Duffy and Kanak's first experiment provided only marginal support, a second experiment in which subjects were selected from more extreme levels of ego strength did provide significant support for the predicted interaction. Further, the associative learning stage, reflected by a measure of the additional trials required from a first-given response to the trial of the first correct response for a given item, was also affected by level of ego strength. High egostrength subjects learning under the anticipation method required significantly more trials to complete this stage than did any of the other three groups.

The purpose of Experiment 1 was to provide an independent replication of the Duffy and Kanak (1975) study and to extend the generality across additional word materials. Experiment 2 extended the investigation to a task that was assumed to include not only intrinsic competition via method of presentation, but also intralist competition via the constitution of the list, using the classic Spence, Farber, and McFann (1956) competitional list. The a priori expectation was that the anticipation method would be inferior to the study/ test method and that this inferiority would be more pronounced with high ego-strength subjects, whose confidence thresholds should be elevated by both sources of competition. 


\section{EXPERIMENT 1}

\begin{abstract}
Method
Design. The study utilized a 2 by 2 by 3 randomized-block design in which subjects of either high or low ego strength were randomly assigned to either the study/test or the anticipation method of presentation and one of three list types, either unassociated or two variations of associatively related items.

Subjects. The participants were 96 individuals selected from a pool of 250 introductory psychology students, who had been administered the Cattell Sixteen Personality Factor Questionnaire (16PF) (Cattell \& Eber, 1962a, 1962b) and whose Factor C (ego strength) scores had been greater or less than the sample mean by 1 standard deviation. Low ego-strength subjects were those with scores of 11 or below, and high ego-strength subjects were those with scores of 18 and above. Subjects received class credit for their participation.

Materials. One of the experimental lists consisted of eight pairs and was formed by pairing 16 associatively unrelated words, as determined by the Palermo and Jenkins (1964) norms. The other list type employed the same stimuli as the first list, but four of the stimuli had their primary associates (Palermo \& Jenkins, 1964) in the response list, although not paired with them. A counterbalanced control list utilizing the remaining four stimuli and their primary associates in the same manner was also constructed. The last two lists were expected to introduce intratask competition, which might cause high ego-strength subjects to be even more inferior to low ego-strength subjects. This manipulation was unsuccessful, as will be reported, but the remaining findings are generalizable across a broader sample of word pairs.
\end{abstract}

All words had a Thorndike and Lorge (1944) frequency count of A or AA. The two types of list were presented via the anticipation or study/test procedure on Lafayette memory drums at a $2: 2-\mathrm{sec}$ rate of presentation with a 4-sec intertrial interval. Four random orders of each list were presented to prevent acquisition of the lists via the serial positioning of the pairs.

Procedure. The procedure consisted of subjects' receiving conventional paired associate instructions and then being required to learn the list of eight pairs to a criterion of two successive perfect trials. After reaching criterion, subjects were debriefed and dismissed.

\section{Results}

With regard to the list manipulation, a measure of trials to criterion indicated no significant main effect for the lists and no interaction with other factors. The analyses of other variables yielded an occasional main effect for lists, but lists did not interact with other factors. When it occurred, the main effect for lists yielded results indicating that one form of the lists involving primary associates of stimulus terms as responses in other pairs was actually less difficult to learn. This result may have been due to unanticipated relationships among items, but the overall lack of a competition effect is probably also due to the relatively short list length and the few competing pairs. Further analyses of list factors will not be reported, since the lack of interaction with other factors fails to limit generalization of other findings across list forms. In addition, in subsequent analyses, only the significant main and/or interaction effects of other variables are reported.

For trials to criterion, the Method by Ego Strength interaction was significant $[F(1,84)=7.42, p=.008]$, with the differences in the predicted directions. The mean trials for high ego strength for the anticipation and study/test methods were 12.56 and 8.00 , respectively, vs. 9.94 and 11.72 for low ego strength.

High ego-strength subjects were expected to yield a higher level of omission errors under the anticipation method than were low ego-strength subjects, as a function of their setting a higher confidence criterion and of that criterion's being further elevated by the competition within the anticipation method. The study/test method, which is free of competition between retrieval and storage processes, was expected to produce superior performance by high ego-strength subjects since performance errors, more likely to be made by low ego-strength subjects, may retard learning and are more likely to be avoided by subjects having a high level of control of responding. The Method by Ego Strength interaction was again in the predicted direction and significant $[F(1,84)=6.25, p=.01]$. Mean total omissions for high ego-strength subjects were 22.80 and 13.53 for the anticipation and study/test methods, respectively, vs. 16.58 and 21.08 for low ego-strength subjects.

If ego strength is an individual difference factor directly affecting willingness to respond, then measures of the trial of first-given responses (i.e., the response learning stage) and omissions within the response learning stage should reflect ego-strength differences, which, in turn, should interact with methods if anticipation involves an intrinsic source of competition. The mean trial to completion of the response learning stage, an average measure of the trial of firstgiven responses across pairs within each subject and indirectly reflecting omissions, produced a Method by Ego Strength interaction $[F(1,84)=5.43, p=.02]$, which is consistent with the prediction and replicates Duffy and Kanak (1975). Means for the high egostrength subjects for the same ordering of the two methods were 2.95 and 2.37 , respectively, compared with 2.43 and 2.93 for low ego-strength subjects. The number of omissions within the response learning stage also supported the hypothesis with a significant interaction $[F(1,84)=4.92, p=.03]$. Means for the high ego-strength subjects were 12.94 and 9.39 for anticipation and study/test, compared with 9.17 and 12.22 for low ego-strength subjects. Further, the same ordering of the means extended to a measure of the associative learning stage, defined stringently as the additional number of trials from a first-given response for a given pair to the trial of two consecutive correct responses for that pair, averaged over pairs within subjects. Again replicating Duffy and Kanak, this measure on the same interaction was significant $[F(1,84)=5.32, p=.02]$. High ego-strength subjects in the anticipation and study/test methods, respectively, produced means of 5.57 and 3.94 , compared with 4.63 and 4.86 for low ego-strength subjects.

An analysis of intralist response intrusions within 
the associative learning stage produced no significant interactions (all ps $>.15$ ), but it did produce a significant method main effect $[F(1,84)=7.21, p=.008]$. The mean number of intrusions under the anticipation method (2.06) was substantially higher than that under the study/test method (.61). This response intrusion evidence provides support for the hypothesis that the anticipation method does contain an intrinsic source of competition in the lack of separation of retrieval and storage processes combined with the rapid alternation from pair to pair in which process is appropriate.

\section{Discussion}

The above two sets of data for omission errors are of particular interest, since the ego-strength hypothesis and the hypothesis that the anticipation method involves inherent competition suggest that response withholding should be greatest for high ego-strength subjects under the anticipation method and least under the competition-free study/test method. Both analyses confirm this effect. These effects and the superiority of low ego-strength subjects under the anticipation method and their inferiority under the study/test method may be due to (1) their more rapid inhibition or extinction of incorrect responding tendencies under the immediate feedback conditions of the anticipation method, associated with their willingness to respond with a lower confidence criterion, but with both factors operating in the opposite direction for high ego-strength subjects, and (2) the fact that the greater willingness to respond earlier with a lower confidence criterion on the part of low ego-strength subjects may be a liability under the study/test method, since the delay of feedback may hamper memory for correctness of previous responding relative to the facilitative effect on such memories produced by the immediate feedback in the anticipation method. High ego-strength subjects, on the other hand, have a higher tendency to withhold responding and, hence, a lower probability of incorrect responding, such that the delay of feedback in the study/test method is relatively less detrimental with respect to the need to inhibit or extinguish incorrect responding tendencies.

\section{EXPERIMENT 2}

\section{Method}

Design. The factors in this study were two levels of ego strength and two methods of presentation. All subjects in this study received the same list.

Subjects. Subjects were 32 students randomly drawn on the basis of ego-strength scores described below, who were tested from two pools of about 200 individuals each who had taken the Cattell 16PF and whose scores on Factor $C$ had been greater or less than the sample mean by 1 standard deviation. Subjects with Factor $\mathrm{C}$ scores of 11 or below were determined to be of low ego strength, and subjects with scores of 19 or above were regarded as high in ego strength. There were thus eight subjects within each of the four conditions. Again, subjects received class credit for their participation.

Materials. The experimental list was the Spence et al. (1956) competition list. The 12 pairs were presented via a slide projector at a 3:3-sec rate of presentation and a 6 -sec intertrial interval, since subjects were required to write their responses. To prevent subjects' reviewing their responses from trial to trial, they were provided with booklets consisting of sheets of paper with 12 lines on only one side of each sheet. As described above, subjects were tested in a group setting and then randomly selected. As in Experiment 1, four random orders of the list were presented to eliminate the possibility of serial learning. Procedure. The procedure was the same as that in Experiment 1.

\section{Results}

As mentioned in the introduction, this experiment used a list (Spence et al., 1956) that is well established as involving intralist competition to test the hypothesis that the inferiority of high ego-strength subjects under the anticipation method and their superiority on the study/test method would both be enhanced if intralist competition interacted with the degree of difficulty inherent in the methods. This hypothesis received no support, since none of the analyses produced a significant Method by Ego Strength interaction. This result could perhaps be due to some combination of the degree of uncontrolled variability associated with the conditions of group testing, the relatively slow pacing of presentation, or the written mode of responding. On the other hand, the data provide some interesting and useful information that warrants questioning of the original hypothesis and suggests ways other than the original hypothesis in which the ego-strength factor may operate in learning highly difficult materials. The data from the experiment are therefore presented in brief form for the significant main effects.

Low ego-strength subjects (mean $=8.94)$ required significantly more trials to reach criterion than high ego-strength subjects (mean $=7.06) \quad[F(1,28)=4.17$, $\mathrm{p}=.05]$. Likewise, low ego-strength subjects took somewhat more trials $(2.60$ vs. 2.14$)$ to complete the response learning stage $[F(1,28)=2.84, p=.09]$ and more trials (4.74 vs. 3.87$)$ to complete the stringently defined associative learning stage $[F(1,28)=3.78$, $\mathrm{p}=.05]$. Low ego-strength subjects also emitted more response intrusions in response learning (3.75 compared with 1.75) $[\mathrm{F}(1,28)=6.94, \mathrm{p}=.01]$ and produced somewhat more omissions in completing the associative learning stage $(12.44$ vs. 6.44$)[F(1,28)=2.79, p=.10]$.

With regard to method effects, the anticipation method failed to be significantly inferior in trials to criterion, although the difference was in the predicted direction (8.19 vs. 7.81). This result is inconsistent with other previous data in our laboratory, not utilizing ego strength as a factor, and the relatively low number of trials to learn implicates the pacing and written response procedures as possible mitigating factors. However, the anticipation method did require significantly more trials ( 4.75 vs. 3.87$)$ to complete the associative learning stage, in which the competitive nature of the list is more prominent $[\mathrm{F}(1,28)=3.87$, $\mathrm{p}=.05]$. Further, the anticipation method produced more response omissions in both the response learning (means $=9.68$ vs. 3.37 ) and associative learning stages (means $=14.56$ and 4.31) $[\mathrm{Fs}(1,28)=4.84$ and 8.17 , respectively, $\mathrm{ps}=.03$ and .008$]$. On the other hand, the anticipation method yielded fewer stimulus intrusions during the response learning stage (means $=1.56$ and 4.56) $[F(1,28)=6.39, \mathrm{p}=.02]$.

\section{GENERAL DISCUSSION}

These analyses of the two main effects in Experiment 2 produce a pattern of findings that offers some potential insight 
into the operation of both ego strength and methods as factors affecting the acquisition of competing associations. Low egostrength subjects required more trials to reach criterion than did high ego-strength subjects. Further, low ego-strength subjects take longer to complete both the response and associative learning stages and, in the process, produce both more response intrusions in the response learning stage, consistent with the notion of a lower level of control over responding tendencies, and more response omissions in the associative stage, when intralist competition is at its highest. It is plausible that the early tendency of low ego-strength subjects to readily emit responses as intrusion errors, consistent with the basic hypothesis, is counteracted by a greater increase in their response-confidence criterion as reflected by the level of response omissions, relative to high ego-strength subjects, when they encounter response generalization in the associative stage. The superior pattern of high ego-strength subjects across these same dependent variables suggests that a high capacity to control responding in the presence of high intralist associative competition becomes a positive factor, since it minimizes erroneous response tendencies that would require later inhibition or extinction if given overtly. The lack of an Ego Strength by Method interaction, previously observed with noncompeting materials, may be due to the fact that (1) the immediate feedback associated with the anticipation method, while facilitating control of incorrect responding for both types of subjects, facilitates such control more for high ego-strength subjects since they have a greater capacity for such control, by definition, in the face of associative competition, and (2) the delay of feedback in the study/test method facilitates "loss of memory" for incorrect responses, which are highest for low ego-strength subjects, and thus reduces the probability of incorrect responding that was evident during response learning and increases the probability of omissions during associative learning.

Since the list involves familiar adjectives not requiring response integration, the length of the response learning stage is probably overestimated, since, as Ekstrand (1966) has pointed out, associative competition results in a heightened confidence threshold for responding. The degree of overestimation is likely to be greatest for the already higher in response-confidence criterion high egostrength subjects (2.14 trials to complete response learning). Therefore, high ego-strength subjects may be assumed to rather rapidly adopt or have more readily available to them some type of superior learning strategy when learning competitional materials under the anticipation method, a method in which they learn simple materials more slowly. The greater control over overt error tendencies that require inhibition or extinction may be a part of the account for this superiority.

The view that immediate feedback associated with the anticipation method is of some importance with competitional materials is supported by the fact that stimulus intrusions during response learning (a nonsignificant variable in Experiment 1) were almost three times greater for the study/test method, involving delay of feedback, than for anticipation. Further, despite the lack of interaction, the intrinsic source of competition in the anticipation method appears to summate with intralist competition. The level of anticipation method response omissions, relative to study/test, was 2.5 times greater in the response learning stage, but 3.33 times greater in the associative stage, in which the summation effects of intralist competition with method difficulty would be strongest. These very substantial absolute differences between the two methods on a measure reflecting response confidence also give further support to the notion that the anticipation method involves an intrinsic form of difficulty or competition directly affecting confidence in responding. The significant inferiority of anticipation in the trials required to complete the associative learning stage, combined with the lack of a method effect on the overall trials-to-criterion measure, also implicates a summation of sources of competition that should be maximal in effect in the associative stage.

The present results suggest some reasons for the typical inferiority of the anticipation method relative to study/test. In addition, however, they provide further evidence that individual difference variables may be essential considerations in understanding the relative efficiency of different methods of learning in interaction with the types of materials to be learned. Further, this evidence has both theoretical and practical application.

Based on the replication of the results of Duffy and Kanak (1975) in Experiment 1 and the results of Experiment 2, the construct of ego strength is viewed as having potentially important and broad ramifications for contemporary theory in learning, memory, and performance, along with other recent endeavors to incorporate other individual difference constructs into the study of learning and performance (Craig, Humphreys, Rocklin, \& Revelle, 1979; Davis \& Frank, 1979; Schwartz, 1979). Further, the results suggest that high ego-strength subjects should be superior on those "controlled" processing tasks (Hasher \& Zacks, 1979; Posner \& Snyder, 1975) that involve competition and processes such as rehearsal and imagery, relative to low egostrength subjects, who are apparently less able to control responding and thus fail to as fully utilize efficient strategies.

\section{REFERENCES}

CAtTell, R. B. Personality and motivation structure and measurement. New York: World Book, 1957.

Cattell, R. B., \& Eber, H. W. Sixteen personality factor questionnaire. Champaign, Ill: Institute for Personality and Ability Testing, 1962. (a)

CATTELl, R. B., \& EBer, H. W. Supplement of norms for Forms $A$ and $B$ of the Sixteen Personality Factor Questionnaire. Champaign, Ill: Institute for Personality and Ability Testing, 1962. (b)

Craig, M. J., Humphreys, M. S., Rocklin, T., \& Revelle, W. Impulsivity, neuroticism, and caffeine: Do they have additive effects on arousal? Journal of Research in Personality, 1979, 13, 404-419.

Davis, J. K., \& Frank, B. M. Learning and memory of field independent-dependent individuals. Journal of Research in Personality, 1979, 13, 469-479.

DuFFY, J. C., \& KANAK, N. J. Ego strength and confidence thresholds in two methods of paired-associate learning. American Journal of Psychology, 1975, 88, 245-252.

Ekstrand, B. R. A note on measuring response learning during paired-associate learning. Journal of Verbal Learning and Verbal Behavior, 1966, 5, 344-347.

HASher, L., \& ZACks, R. T. Automatic and effortful processes in memory. Journal of Experimental Psychology: General, 1979, 108, 356-388.

KanaK, N. J., \& Neuner, S. D. Associative symmetry and item availability as a function of five methods of paired-associate acquisition. Journal of Experimental Psychology, 1970, 86, 288-295.

Pale rmo; D. S., \& Jenkins, J. J. Word association norms: Grade school through college. Minneapolis: University of Minnesota Press, 1964.

Posner, M. I., \& Snyder, C. R. R. Attention and cognitive control. In R. L. Solso (Ed.), Information processing and cognition: The Loyola symposium. Hillsdale, N.J: Erlbaum, 1975.

Schwartz, S. Differential effects of personality on access to various long-term memory codes. Journal of Research in Personality, 1979, 13, 396-403.

Spence, K. W., Farber, I. E., \& McFann, H. H. The relation of anxiety (drive) level to performance in competitional and non-competitional paired-associate learning. Journal of Experimental Psychology, 1956, 52, 296-305.

Thorndike, E. L., \& Lorge, I. The teacher's book of 30,000 words. New York: Teacher's College, Columbia University, Bureau of Publications, 1944.

UNDE RWOOD, B. J., \& Schulz, R. W. Meaningfulness and verbal learning. Philadelphia: Lippincott, 1960.

(Received for publication November 14, 1981.) 